\title{
PENENTUAN RAINBOW CONNECTION NUMBER PADA GRAF BUKU SEGIEMPAT, GRAF KIPAS, DAN GRAF TRIBUN
}

\author{
FITRI ANGGALIA \\ Program Studi Matematika, \\ Fakultas Matematika dan Ilmu Pengetahuan Alam, Universitas Andalas, \\ Kampus UNAND Limau Manis Padang, Indonesia, \\ email : fitri.anggalia@gmail.com
}

\begin{abstract}
Abstrak. Misalkan $G$ adalah suatu graf terhubung tak trivial. Suatu pewarnaan $c: E(G) \rightarrow\{1,2, \cdots, k\}, k \in \mathbb{N}$ pada graf $G$ adalah suatu pewarnaan sisi di $G$ sedemikian sehingga setiap sisi bertetangga boleh berwarna sama. Misalkan $u, v \in V(G)$ dan $P$ adalah suatu lintasan dari $u$ ke $v$. Suatu intasan $P$ dikatakan rainbow path jika tidak terdapat dua sisi di $P$ berwarna sama. Graf $G$ disebut rainbow connected dengan pewarnaan $c$ jika untuk setiap $u, v \in V(G)$ terdapat rainbow path dari $u$ ke $v$. Jika terdapat $k$ warna di $G$ maka $c$ adalah rainbow k-coloring. Rainbow connection number dari graf terhubung dinotasikan dengan $r c(G)$, didefinisikan sebagai banyaknya warna minimal yang diperlukan untuk membuat graf $G$ bersifat rainbow connected.

Dalam makalah ini akan ditentukan rainbow connection number pada graf buku segiempat $\mathfrak{B}_{n}$ yang merupakan hasil dari operasi amalgamasi sisi pada graf Cycle $C_{4}$, graf Kipas $F_{n}$ dengan $n \geq 2$ yang merupakan hasil dari operasi joint dari Path $P_{n}$ dengan graf lengkap $K_{1}$, dan Graf $\mathfrak{T}_{n}=\operatorname{shack}(\operatorname{tribun}, n)$ yang merupakan hasil dari operasi shackle pada graf tribun.
\end{abstract}

Kata Kunci: Rainbow connection number, amalgamasi sisi, graf buku segiempat, graf kipas, graf tribun

\section{Pendahuluan}

Rainbow connection pada graf pertama kali diperkenalkan pada tahun 2006 oleh Chartrand dkk [2]. Misalkan $G$ adalah graf terhubung tak trivial dan didefinisikan pewarnaan sisi $c: E(G) \rightarrow\{1,2, \cdots, k\}$ dengan $k \in N$, sedemikian sehingga dua sisi yang bertetangga boleh memiliki warna yang sama. Suatu $u-v$ path $P$ di $G$ dikatakan rainbow path jika tidak ada dua sisi di $P$ yang memiliki warna sama. Graf $G$ dikatakan rainbow connected jika setiap dua titik yang berbeda di $G$ dihubungkan oleh rainbow path. Minimum dari banyak warna sehingga suatu graf menjadi rainbow connected disebut dengan rainbow connection number, dinotasikan $r c(G)$.

Konsep rainbow connection dapat digunakan untuk pengamanan pengiriman informasi rahasia antar pemerintah dan agen. Dalam hal ini, pemerintah dan agen tidak diizinkan untuk saling mencek informasi karena berhubungan dengan keamanan nasional, sehingga informasi kepada agen satu dan lainnya harus menggunakan sandi. Dengan demikian, akan terdapat satu atau lebih lintasan informasi untuk setiap dua agen dan harus dipastikan tidak ada sandi yang berulang. Kata sandi setiap lintasan harus berbeda, sehingga harus ditentukan banyaknya sandi 
yang dibutuhkan, agar terdapat satu lintasan yang aman antara dua agen. Situasi inilah yang dimodelkan menjadi konsep rainbow connection number. Pada makalah ini akan dibahas tentang rainbow connection number pada graf buku segiempat, graf kipas, dan graf tribun.

Graf Buku Segiempat $\mathfrak{B}_{n}$ merupakan hasil dari operasi amalgamasi sisi pada Graf Cycle $C_{4}[5]$ seperti pada Gambar 1 . Graf Kipas $F_{n}$ dengan $n \geq 2$ merupakan

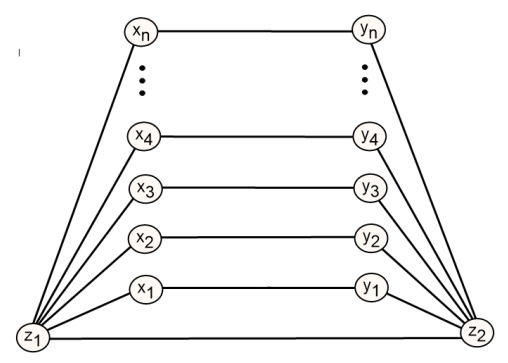

Gambar 1. Graf Buku Segiempat $\mathfrak{B}_{n}$

hasil dari operasi joint dari Graf Path $P_{n}$ dengan Graf Lengkap $K_{1}$ sehingga dapat

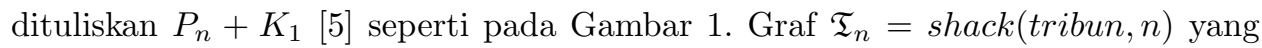

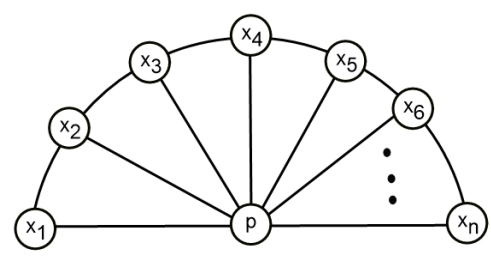

Gambar 2. Graf Kipas $F_{n}$

merupakan hasil dari operasi shackle pada Graf Tribun [5] seperti pada Gambar 3.

Pada Proposisi 1.1 diberikan hubungan antara $\operatorname{diam}(G), \operatorname{rc}(G), \operatorname{src}(G)$ dan banyak sisi $m$ pada suatu graf terhubung $G$.

Proposisi 1.1. [2] Misalkan $G$ adalah graf terhubung tak trivial berukuran $m$. Jika $c: E(G) \rightarrow\{1,2, \cdots, k\}, k \in \mathbb{N}$ merupakan rainbow coloring, maka

$$
\operatorname{diam}(G) \leq r c(G) \leq \operatorname{src}(G) \leq m .
$$

\section{Penentuan Rainbow Connection Number pada Graf Buku Segiempat, Graf Kipas, dan Graf Tribun}

Pada Teorema 2.1 diberikan bilangan rainbow connection pada graf buku segiempat.

Teorema 2.1. [5] Untuk $n \geq 1$ rainbow connection number dari graf buku segiem- 


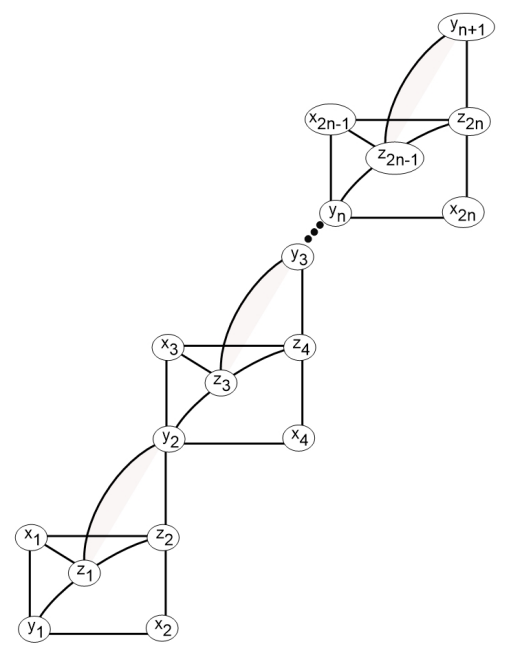

Gambar 3. graf $\mathfrak{T}_{n}=\operatorname{shack}(\operatorname{tribun}, n)$

pat $\mathfrak{B}_{n}$ adalah

$$
r c\left(\mathfrak{B}_{n}\right)=\left\{\begin{array}{l}
2, \text { untuk } n=1 \\
3, \text { untuk } n=2 \text { dan } n=3, \\
4, \text { untuk } n \geq 4 .
\end{array}\right.
$$

Bukti. Graf buku segiempat $\mathfrak{B}_{n}$ adalah graf dengan himpunan titik dan himpunan sisi sebagai berikut.

$$
\begin{aligned}
& V\left(\mathfrak{B}_{n}\right)=\left\{z_{1}, z_{2}, x_{i}, y_{i}, 1 \leq i \leq n\right\}, \\
& E\left(\mathfrak{B}_{n}\right)=\left\{z_{1} z_{2}\right\} \cup\left\{z_{1} x_{i} \cup z_{2} y_{i} ; 1 \leq i \leq n\right\} \cup\left\{x_{i} y_{i} ; 1 \leq i \leq n\right\} .
\end{aligned}
$$

Banyak titik pada graf $\mathfrak{B}_{n}$ yaitu $\left|V\left(\mathfrak{B}_{n}\right)\right|=2(n)+2$ dan banyak sisi pada graf $\mathfrak{B}_{n}$ yaitu $\left|E\left(\mathfrak{B}_{n}\right)\right|=3(n)+1$. Pandang beberapa kasus berikut.

Kasus 1. $n=1$.

Definisikan $c_{1}: E\left(\mathfrak{B}_{n}\right) \rightarrow\{1,2\}$ sebagai berikut.

$$
c_{1}(e)= \begin{cases}1, & \text { jika } e=z_{1} x_{1} \text { dan } z_{2} y_{1} \\ 2, & \text { jika } e=z_{1} z_{2} \text { dan } x_{1} y_{1}\end{cases}
$$

Berdasarkan pewarnaan tersebut dapat dilihat bahwa $r c\left(\mathfrak{B}_{1}\right) \leq 2$. Selanjutnya, dapat dilihat bahwa $\operatorname{diam}\left(\mathfrak{B}_{1}\right)=2$, sehingga berdasarkan Proposisi 1.1, berlaku $r c\left(\mathfrak{B}_{1}\right) \geq 2$. Maka diperoleh bahwa $r c\left(\mathfrak{B}_{1}\right)=2$.

Kasus 2. $n=2$.

Definisikan $c_{2}: E\left(\mathfrak{B}_{2}\right) \rightarrow\{1,2,3\}$ sebagai berikut.

$$
c_{2}(e)=\left\{\begin{array}{l}
1, \text { jika } e=z_{1} x_{1} \text { dan } z_{2} y_{1}, \\
2, \text { jika } e=z_{1} x_{2} \text { dan } z_{2} y_{2}, \\
3, \text { jika } e=z_{1} z_{2} \text { dan } x_{i} y_{i}, \text { untuk } 1 \leq i \leq n .
\end{array}\right.
$$


Berdasarkan definisi pewarnaan tersebut, jelas bahwa $r c\left(\mathfrak{B}_{2}\right) \leq 3$. Selanjutnya dapat dilihat bahwa $\operatorname{diam}\left(\mathfrak{B}_{2}\right)=3$, sehingga berdasarkan Proposisi $1.1, \operatorname{rc}\left(\mathfrak{B}_{2}\right) \geq 3$. Maka diperoleh bahwa $r c\left(\mathfrak{B}_{2}\right)=3$.

Kasus 3. $n=3$.

Definisikan $c_{3}: E\left(\mathfrak{B}_{3}\right) \rightarrow\{1,2,3\}$ sebagai berikut.

$$
c_{3}(e)=\left\{\begin{array}{l}
1, \text { jika } e=z_{1} x_{1}, e=z_{2} y_{1}, e=x_{3} y_{3} \text { dan } z_{1} z_{2}, \\
2, \text { jika } e=z_{1} x_{2}, e=z_{2} y_{2} \text { dan } x_{2} y_{2}, \\
3, \text { jika } e=z_{1} x_{3}, e=z_{2} y_{3} \text { dan } x_{1} y_{1} .
\end{array}\right.
$$

Berdasarkan definisi pewarnaan tersebut, jelas bahwa $r c\left(\mathfrak{B}_{3}\right) \leq 3$. Selanjutnya, dapat dilihat bahwa $\operatorname{diam}\left(\mathfrak{B}_{3}\right)=3$, sehingga berdasarkan Proposisi 1.1, $\operatorname{rc}\left(\mathfrak{B}_{3}\right) \geq 3$. Maka diperoleh bahwa $\operatorname{rc}\left(\mathfrak{B}_{3}\right)=3$.

Kasus 4. $n \geq 4$.

Definisikan $c_{4}: E\left(\mathfrak{B}_{n}\right) \rightarrow\{1,2,3,4\}$ sebagai berikut.

$$
c_{4}(e)=\left\{\begin{array}{l}
1, \text { jika } e=z_{1} x_{i} \text { untuk } 1 \leq i \leq n, \\
2, \text { jika } e=z_{2} y_{i} \text { untuk } 1 \leq i \leq n, \\
3, \text { jika } e=x_{i} y_{i} \text { untuk } 1 \leq i \leq n, \\
4, \text { jika } e=z_{1} z_{2} .
\end{array}\right.
$$

Berdasarkan definisi pewarnaan tersebut, jelas bahwa $r c\left(\mathfrak{B}_{n}\right) \leq 4$. Selanjutnya, karena $\operatorname{diam}\left(\mathfrak{B}_{n}\right)=3$, maka berdasarkan Proposisi $1.1, \operatorname{rc}\left(\mathfrak{B}_{n}\right) \geq 3$.

Akan ditunjukkan bahwa $r c\left(\mathfrak{B}_{n}\right) \neq 3$. Misalkan $c^{\prime}$ adalah suatu rainbow 3coloring dari $\mathfrak{B}_{n}$ untuk $n \geq 4$, dapat dilihat pada Gambar 4. Dengan memberi

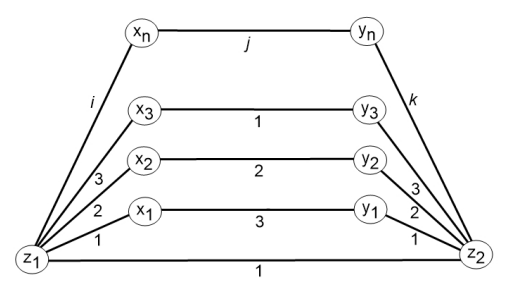

Gambar 4. $r c\left(\mathfrak{B}_{n}\right)=3$ dengan $i \in\{1,2,3\}, j \in\{1,2,3\}, k \in\{1,2,3\}$

warna $c^{\prime}\left(z_{1} x_{n}\right)=1$, maka tidak terdapat rainbow $x_{n}-x_{1}$ path di $\mathfrak{B}_{n}$. Sementara jika $c^{\prime}\left(z_{1} x_{n}\right)=2$ maka tidak terdapat rainbow $x_{n}-x_{2}$ path di $\mathfrak{B}_{n}$. Jika $c^{\prime}\left(z_{1} x_{n}\right)=3$ maka tidak terdapat rainbow $x_{n}-x_{3}$ path di $\mathfrak{B}_{n}$. Selanjutnya jika diberikan warna $c^{\prime}\left(z_{2} y_{n}\right)=1$ maka tidak terdapat rainbow $y_{n}-y_{1}$ path di $\mathfrak{B}_{n}$. Sementara jika $c^{\prime}\left(z_{1} y_{n}\right)=2$ maka tidak terdapat rainbow $y_{n}-y_{2}$ path di $\mathfrak{B}_{n}$. Jika $c^{\prime}\left(z_{1} y_{n}\right)=3$ maka tidak terdapat rainbow $y_{n}-y_{3}$ path di $\mathfrak{B}_{n}$.

Berdasarkan pewarnaan tersebut, jelas bahwa $r c\left(\mathfrak{B}_{n}\right) \neq 3$, sehingga haruslah $r c\left(\mathfrak{B}_{n}\right) \geq 4$. Maka diperoleh bahwa $\operatorname{rc}\left(\mathfrak{B}_{n}\right)=4$ untuk $n \geq 4$.

Gambar 5 merupakan gambar pewarnaan rainbow pada graf $\mathfrak{B}_{n}$.

Pada Teorema 2.2 diberikan bilangan Rainbow Connection pada graf kipas. 


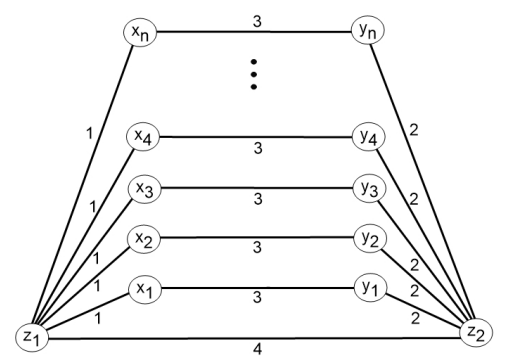

Gambar 5. Rainbow coloring pada graf $\mathfrak{B}_{n}$

Teorema 2.2. [7] Untuk $n \geq 2$, rainbow connection number dari graf kipas $F_{n}$ adalah

$$
r c\left(F_{n}\right)=\left\{\begin{array}{l}
1, \text { untuk } n=2 \\
2, \text { untuk } 3 \leq n \leq 6 \\
3, \text { untuk } n \geq 7
\end{array}\right.
$$

Bukti. Graf kipas $F_{n}$ adalah graf dengan memiliki himpunan titik dan himpunan sisi sebagai berikut.

$$
\begin{aligned}
& V\left(F_{n}\right)=\left\{x_{i}, P ; 1 \leq i \leq n\right\}, \\
& E\left(F_{n}\right)=\left\{x_{i} x_{i+1} ; 1 \leq i \leq n-1, P x_{i} ; 1 \leq i \leq n\right\} .
\end{aligned}
$$

Banyak titik pada graf $F_{n}$ yaitu $\left|V\left(F_{n}\right)\right|=n+1$ dan banyak sisi pada graf $F_{n}$ yaitu $\left|E\left(F_{n}\right)\right|=2(n)-1$. Pandang beberapa kasus berikut.

Kasus 1. $n=2$.

Definisikan $c_{5}: E\left(F_{n}\right) \rightarrow\{1\}$ sebagai berikut.

$$
c_{5}(e)=1, e=x_{1} x_{2}, e=P x_{1}, e=P x_{2} .
$$

Berdasarkan pewarnaan tersebut, jelas bahwa $r c\left(F_{2}\right) \leq 1$. Selanjutnya karena $\operatorname{diam}\left(F_{2}\right)=1$ maka berdasarkan Proposisi 1.1, berlaku bahwa $r c\left(F_{2}\right) \geq 1$. Dapat disimpulkan bahwa $r c\left(F_{2}\right)=1$.

Kasus 2. $3 \leq n \leq 6$.

Definisikan $c_{6}: E\left(F_{n}\right) \rightarrow\{1,2\}$ sebagai berikut.

$$
c_{6}(e)=\left\{\begin{aligned}
1, e & =P x_{i}, \text { untuk } 1 \leq i \leq 3, \\
e & =x_{i} x_{i+1} \text { untuk } i \text { ganjil }, 1 \leq i \leq 3, \\
2, e & =P x_{i} \text { untuk } 4 \leq i \leq 6, \\
e & =x_{i} x_{i+1} \text { untuk } i \text { genap } 1 \leq i \leq 3 .
\end{aligned}\right.
$$

Berdasarkan pewarnaan tersebut, jelas bahwa $r c\left(F_{n}\right) \leq 2$ untuk $3 \leq n \leq 6$. Selanjutnya karena $\operatorname{diam}\left(F_{n}\right)=2$ maka berdasarkan Proposisi 1.1, berlaku bahwa $r c\left(F_{n}\right) \geq 2$. Dapat disimpulkan bahwa $r c\left(F_{n}\right)=2$ untuk $3 \leq n \leq 6$. 
Kasus 3. $n \geq 7$.

Definisikan $c_{7}: E\left(F_{n}\right) \rightarrow\{1,2,3\}$ sebagai berikut.

$$
c_{7}(e)=\left\{\begin{array}{l}
1, e=x_{i} x_{i+1} \text { untuk } 1 \leq i \leq n, \\
2, e=P x_{i} \text { untuk } i \text { ganjil }, 1 \leq i \leq n, \\
3, e=P x_{i} \text { untuk } i \text { genap }, 1 \leq i \leq n .
\end{array}\right.
$$

Berdasarkan pewarnaan tersebut, jelas bahwa $r c\left(F_{n}\right) \leq 3$ untuk $n \geq 7$. Selanjutnya, karena $\operatorname{diam}\left(F_{n}\right)=2$ maka berdasarkan Proposisi 1.1 diperoleh $r c\left(F_{n}\right) \geq 2$.

Akan ditunjukkan $r c\left(F_{n}\right) \neq 2$ sehingga $r c\left(F_{n}\right) \geq 3$. Misalkan $c^{\prime}$ adalah suatu rainbow 2-coloring dari $F_{n}$ untuk $n \geq 7$. Warnai graf $F_{n}$, untuk $n \geq 7$ dengan pewarnaan graf $F_{n}$ untuk $3 \leq n \leq 6$. Pewarnaan tersebut dapat dilihat pada Gambar 6. Dengan memberi warna $c^{\prime}\left(P x_{n}\right)=1$ maka tidak terdapat rainbow path

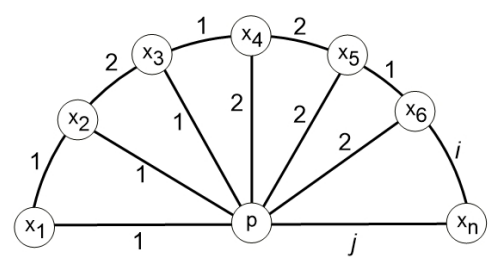

Gambar 6. $r c\left(F_{n}\right)=2$ dengan $i \in\{1,2\}$

pada lintasan yang menghubungkan $x_{1}$ ke $x_{n}$ pada $F_{n}$. Jika $c^{\prime}\left(P x_{n}\right)=2$ maka tidak terdapat rainbow path pada lintasan yang menghubungkan $x_{1}$ ke $x_{4}$ pada $F_{n}$. Ini membuktikan bahwa $r c\left(F_{n}\right) \neq 2$ sehingga haruslah $r c\left(F_{n}\right) \geq 3$. Dengan demikian dapat dibuktikan bahwa $r c\left(F_{n}\right)=3$.

Gambar 7 merupakan gambar pewarnaan rainbow pada graf $F_{n}$.

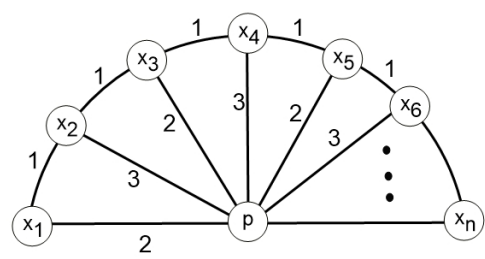

Gambar 7. $F_{n}$ dengan $r c\left(F_{n}\right)=3$

Pada Teorema 2.3 diberikan rainbow connection number untuk graf tribun.

Teorema 2.3. [5] Nilai rainbow connection number untuk graf $\mathfrak{T}_{n}=$ $\operatorname{shack}($ Tribun, $n)$ adalah $\operatorname{rc}\left(\mathfrak{T}_{n}\right)=2 n$.

Bukti. Graf $\mathfrak{T}_{n}=\operatorname{shack}($ tribun, $n)$ adalah hasil graf shackle (belenggu) sebuah graf tribun sebanyak $n$ kali, dengan himpunan titik dan himpunan sisi sebagai 
berikut.

$V\left(\mathfrak{T}_{n}\right)=\left\{x_{i}, z_{i}, y_{j} ; 1 \leq i \leq 2 n ; 1 \leq j \leq n+1\right\}$,

$E\left(\mathfrak{T}_{n}\right)=\left\{x_{i} z_{i} ; i\right.$ ganjil, $\left.1 \leq i \leq 2 n\right\} \cup\left\{y_{j} x_{2 j-1} ; 1 \leq j \leq n\right\} \cup\left\{z_{i} y_{j+1} ; i\right.$ genap, $\left.1 \leq i \leq 2 n ; 1 \leq j \leq n\right\}$ $\cup\left\{y_{j} z_{2 j-1} ; 1 \leq j \leq n\right\} \cup\left\{z_{i} z_{i+1} ; i\right.$ ganjil, $\left.1 \leq i \leq 2 n\right\} \cup\left\{y_{j} x_{2 j} ; 1 \leq j \leq n\right\}$

$\cup\left\{x_{i} z_{i} ; i\right.$ genap, $\left.1 \leq i \leq 2 n\right\} \cup\left\{z_{i} y_{j+1} ; i\right.$ ganjil, $\left.1 \leq i \leq 2 n, 1 \leq j \leq n\right\}$

$\cup\left\{z_{i} x_{i-1} ; i\right.$ genap, $\left.1 \leq i \leq 2 n\right\}$

Dapat dilihat bahwa $\left|V\left(\mathfrak{T}_{n}\right)\right|=5 n+1$ dan $\left|E\left(\mathfrak{T}_{n}\right)\right|=9 n$.

Definisikan $c_{8}: E\left(F_{n}\right) \rightarrow\{1,2, \cdots, 2 n\}$ sebagai berikut.

$$
c_{8}(e)= \begin{cases}i-1, & e=x_{i} z_{i} \text { untuk } i \text { genap, } 1 \leq i \leq 2 n, \\ 2 j-1, & e=y_{j} x_{2 j-1} \text { untuk } y_{j} z_{2 j-1}, \text { untuk } 1 \leq j \leq n, \\ i, & e=x_{i} z_{i} \text { untuk } i \text { ganjil, } 1 \leq i \leq 2 n, \\ e & =z_{i} x_{i-1} \text { untuk } i \text { genap, } 1 \leq i \leq 2 n, \\ & e=z_{i} y_{j+1} \text { untuk } i \text { genap, } 1 \leq i \leq 2 n ; 1 \leq j \leq n, \\ 2 j, & e=y_{j} x_{2 j} \text { untuk } 1 \leq j \leq n, \\ i+1, & e=z_{i} z_{i+1} \text { untuk } i \text { ganjil, } 1 \leq i \leq 2 n, \\ & e=z_{i} y_{j+1} \text { untuk } i \text { ganjil, } 1 \leq i \leq 2 n ; 1 \leq j \leq n .\end{cases}
$$

Berdasarkan definisi pewarnaan pada graf $\mathfrak{T}_{n}$, diperoleh bahwa $r c\left(\mathfrak{T}_{n}\right) \leq 2 n$. Selanjutnya, karena $\operatorname{diam}\left(\mathfrak{T}_{n}\right)=2 n$, maka berdasarkan Proposisi 1.1, $r c\left(\mathfrak{T}_{n}\right) \geq 2 n$. Sehingga dapat dibuktikan bahwa $r c\left(\mathfrak{T}_{n}\right)=2 n$.

Gambar 8 merupakan pewarnaan rainbow pada graf $\mathfrak{T}_{n}=\operatorname{shack}(\operatorname{tribun}, n)$.

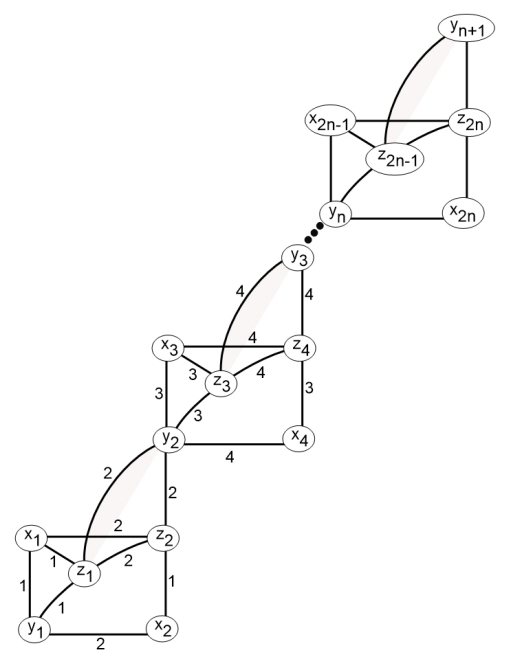

Gambar 8. Graf $\mathfrak{T}_{n}$ dengan $\operatorname{rc}\left(\mathfrak{T}_{n}\right)=2 n$ 
160 Fitri Anggalia

\section{Kesimpulan}

Pada makalah ini telah dikaji kembali makalah [5] tentang penentuan rainbow connection number pada graf buku segiempat $\mathfrak{B}_{n}$, graf kipas $F_{n}$ dan graf Tribun $\mathfrak{T}_{n}$ sebagai berikut.

(1) Rainbow connection number untuk graf buku segiempat $\mathfrak{B}_{n}$ adalah

$$
\operatorname{rc}\left(\mathfrak{B}_{n}\right)=\left\{\begin{array}{l}
2, \text { untuk } n=1, \\
3, \text { untuk } n=2 \text { dan } n=3, \\
4, \text { untuk } n \geq 4 .
\end{array}\right.
$$

(2) Rainbow connection number untuk graf kipas $F_{n}$ adalah

$$
r c\left(F_{n}\right)=\left\{\begin{array}{l}
1, \text { untuk } n=2, \\
2, \text { untuk } 3 \leq n \leq 6, \\
3, \text { untuk } n \geq 7 .
\end{array}\right.
$$

(3) Rainbow connection number untuk graf tribun $\mathfrak{T}_{n}$ adalah

$$
r c\left(\mathfrak{T}_{n}\right)=2 n .
$$

\section{Ucapan Terima Kasih}

Penulis mengucapkan terima kasih kepada Bapak Prof. Dr. Syafrizal Sy, Bapak Dr. Effendi, Ibu Dr. Lyra Yulianti, Bapak Narwen, M.Si, Bapak Budi Rudianto, M.Si yang telah memberikan masukan dan saran sehingga makalah ini dapat diselesaikan dengan baik.

\section{Daftar Pustaka}

[1] Bondy, J. A. dan U. S. R. Murty. 1976. Graph Theory with Applications. Macmillan, London.

[2] Chartrand, G. dkk. 2008. Rainbow Connection in Graph, Mathematica Bohemica. 133: $85-98$

[3] Darmawan, R. N. 2015. Analisis Rainbow Connection Number pada Graf Khusus dan Hasil Operasinya. Tesis S-2, tidak dipublikasikan. Universitas Jember, Jember.

[4] Li, X. dan Sun, Y. 2012. Rainbow Connection of Graphs. Springer, New York.

[5] Mahmudah, M. dan Dafik. Rainbow Connection hasil operasi graf. Prosiding Seminar Nasional Matematika 2014 Universitas Jember hal. 174 - 183

[6] Mahmudah, M. Dafik dan Slamin. Super $(a, d)$-Edge Antimagic Total Labeling Of Connected Tribun Graph. Kadikma. 6(3) : 115 - 122

[7] Medika, G.H. Syafrizal Sy. Yulianti, Lyra. The Rainbow Connection of Fan and Sun. Applied Mathematical Sciences. 7(64): 3155 - 3159

[8] N. L. Biggs, R. J. Lloyd dan R. J. Wilson. 1986. Graph Theory 1736-1936. Clarendon Press, Oxford. 